\title{
Increases in Faculty Publishing Activity: An Analysis of ARL and ACRL Institutions
}

\author{
John M. Budd
}

This study builds on a previous one that focused on publishing productivity of faculty at ARL institutions for the period 1991-1993. The present research expands the analysis to the period 1995-1997 and adds an examination of faculty activity at selected ACRL institutions for the two time periods. Measures of total publications and per capita publications per institution increased significantly for both groups over the two time periods. The increases indicate that, for what is likely to be a complex set of factors, faculty feel the need to communicate more and are turning to traditional print outlets for at least some of the communication. Deliberations on the future of scholarly communication should incorporate the views and practices of faculty.

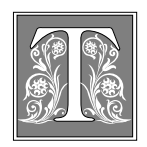

here is concern across all areas of higher education about what is frequently termed the "serials crisis," but what is actually a crisis of access to information. Librarians and faculty share the concern regarding institutions' ability to afford access (through purchase, subscription, or some kind of licensing) to the products of research and scholarship. The serials dilemma is analyzed as part of a larger study by Stephen J. Bensman and Stanley Wilder, who offer an extensive review of the literature on the subject. ${ }^{1}$ One largescale effort to respond to the challenge of access is the Scholarly Publishing and Academic Resources Coalition (SPARC), sponsored by the Association of Research Libraries (ARL) and endorsed by several other associations. ${ }^{2}$ This effort is aimed at promoting a more effective means of sharing research and scholarship, thus enhancing institutions' ability to provide information access for their members.

Another approach to the problem focuses on the production of information. Stephen D. Gruning reports that research is a principal factor in assessing both the undergraduate and graduate reputations of a sample of public and private universities. ${ }^{3}$ Meredith Jane Ludwig maintains that faculty research has the potential to contribute to an integrated and holistic fulfillment of institutions' missions. ${ }^{4}$ John M. Braxton and Joseph B. Berger review the literature on faculty productivity and find that publishing and research activities have beneficial (improved course content and teacher effectiveness) and detrimental (lessened rigor of examinations and less prompt feedback to students) effects on teaching. ${ }^{5}$ The debate on the proper role for faculty and the proper emphasis on research and publication has

John M. Budd is an Associate Professor in the School of Information Science and Learning Technologies at the University of Missouri-Columbia; e-mail: libsjmb@showme.missouri.edu. 
led some to reconceive the definition of productivity. Ernest L. Boyer's Scholarship Reconsidered and a more recent follow-up to that proposal, Scholarship Assessed, question the efficacy of reward systems that perpetuate the production of numerous publications. ${ }^{6-7}$

The central question asked here is: Has there been any observable change in recent years in publishing patterns by faculty?

Studies of the effects of faculty publishing may be enlightening, but they address only a portion of the issue. All commentators on the subject can agree that the matter of access to information for scholarly purposes is complex. Although the efforts to investigate matters of access are necessary, there also is the need to examine the production of information objects (such as journal articles). The present study analyzes publishing patterns of faculty at selected universities. The central question asked here is: Has there been any observable change in recent years in publishing patterns by faculty?

\section{Description of the Study}

This study builds on an earlier one conducted by John M. Budd. ${ }^{8}$ That project, prompted by observations that quantity of publication is important as an assessment of productivity, focused on measures of faculty publishing. It included an examination of publishing by faculty at ARL institutions for the period 1991 through 1993 and used Science Citation Index, Social Sciences Citation Index, and Arts and Humanities Citation Index as sources of data. The present study extends that earlier one in two ways. First, it looks to compare the earlier findings to a more recent time period, 1995 through 1997. Second, it adds a study of publishing by faculty at institutions included in the ACRL university library population. The latter group is studied over the two time periods.

As was the case with the earlier study, this examination also uses the citation indexes as sources of data. The indexes allow for searching by corporate source, so each university can be searched to determine the number of publications by its faculty. The same disclaimers and caveats that applied to the previous study also hold here. The citation indexes do not allow for the measure of numbers of books, book chapters, and conference proceedings. Further, they do not cover the universe of journal titles; rather, they index a small and select subset of that universe. For these reasons, the figures that are reported here do not represent total publications but, rather, a portion of total publications. Because the citation indexes are selective in their coverage, it is inferred that publications in the indexed journals are some, albeit imperfect and limited, indication of quality.

Other limitations of the earlier study apply to the present one. The main campus of each university is searched as a corporate source. Branch campuses are not included. In some particular instances, such as the University of California, separate campuses that are individual members of ARL are searched separately. In some other instances, medical schools are not housed with the main campus, but may be in a different city. Attempting to include geographically remote medical schools remains problematic, so they are not included as part of the universities' publication totals. If the medical school is included within the corporate source index for the main campus, the publications by medical school faculty are counted. As a result of this anomaly, institutional rankings are not absolutely accurate and representative. Rankings should be taken as relative measures of productivity. The same definition of publication is used in this study as in the earlier one. Anything that is designated as an "article" in the citation indexes is included. This means that editorials, book reviews, bibliographies, and so on are not counted.

\section{Findings: ARL Institutions}

As was reported in the earlier study, the mean number of publications per institution for the 1991-1993 period is $4,595.8$. 


\begin{tabular}{|lrlr|}
\hline \multicolumn{4}{c}{ TABLE 1 } \\
\multicolumn{4}{|c}{$\begin{array}{c}\text { Top Twenty ARL Institutions Compared: } \\
\text { Total Number of Publications }\end{array}$} \\
\hline \hline \multicolumn{3}{c}{ 1991-1993 } & \multicolumn{2}{c}{$1995-1997$} \\
\hline Harvard & 16,945 & Harvard & 21,913 \\
UCLA & 12,566 & UCLA & 13,620 \\
MIT & 11,788 & Michigan & 13,006 \\
Michigan & 10,907 & UC Berkeley & 12,237 \\
U. of Washington & 10,645 & U. of Washington & 12,117 \\
Cornell & 10,518 & Minnesota & 11,369 \\
UC Berkeley & 10,378 & Stanford & 11,169 \\
Minnesota & 10,304 & Wisconsin & 10,952 \\
Stanford & 9,723 & Cornell & 10,918 \\
Wisconsin & 9,663 & Johns Hopkins & 10,576 \\
Johns Hopkins & 9,636 & Pennsylvania & 10,247 \\
Pennsylvania & 8,636 & UC San Diego & 10,059 \\
Illinois & 7,884 & Pittsburgh & 9,148 \\
Columbia & 7,824 & Yale & 8,938 \\
Yale & 7,779 & Columbia & 8,886 \\
UC San Diego & 7,732 & MIT & 8,732 \\
UC Davis & 7,621 & Ohio State & 8,552 \\
Ohio State & 7,155 & Penn State & 8,543 \\
Pittsburgh & 7,155 & Illinois & 8,400 \\
Penn State & 6,925 & UC Davis & 8,389 \\
& & & \\
\hline
\end{tabular}

number of publications per institution for the two time periods.

$\mathrm{H}_{2}$ There is no statistically significant difference between the mean per capita number of publications for the two time periods.

For purposes of testing and analysis, the type I error level (the probability of rejecting a true null hypothesis) used is 0.05 .

In each instance, a paired t-test is employed to determine statistical significance. In the first case, the mean num-

The range is 669 to 16,945 . For 1995-1997, the mean number of publications is $5,493.5$, an increase of nearly 900 publications per institution. The range is 659 to 21,913 . A comparison of the top twenty institutions by total publications for the two time periods is presented in table 1 .

A similar trend is apparent for per capita publications. For the earlier period, the mean per capita number of publications is 3.56, with a low of 0.50 and a high of 12.71 . In the more recent period, the mean rises to 4.20 , with a low of 0.53 and a high of 12.94. Table 2 presents a comparison of the top twenty institutions by per capita publications for the time periods.

These data may hold some interest in themselves but, more important, they allow for testing of some hypotheses. Two hypotheses regarding the data from the two time periods (stated as null hypotheses) are posed here:

$\mathrm{H}_{1}$ There is no statistically significant difference between the mean ber of publications per institution, the calculated probability is less than 0.001 . In the second case, the mean per capita number of publications, the calculated probability is also less than 0.001 . Both of the null hypotheses are rejected; there are statistically significant differences between the two time periods.

The mean figures for total and per capita publications suggest the magnitude of the difference over the two time periods. Because the same data source is used for the two time periods, the reasons for the differences can only be speculated on. The pressure on faculty at research universities to publish is certainly great today, but it also was substantial in the early 1990s. It may be that there has been some turnover in the faculties; some individuals in the senior ranks may have retired in recent years. The faculty who have replaced those who have retired may be more sensitized to the need to publish. Further, the faculty who have been hired more recently may be in jun- 


\begin{tabular}{|lrlr|}
\hline \multicolumn{4}{c}{ TABLE 2 } \\
Top Twenty \\
ARL Institutions Compared: \\
Per Capita Publications
\end{tabular}

culated, comparing the rankings of the ARL institutions for the two time periods. When rank-order correlation is computed for total publications, the correlation coefficient is .98 . This is a very strong positive correlation, suggesting that there is little variance in the rankings from 19911993 to $1995-1997$. The correlation coefficient for per capita publications is .81 , a slightly less strong positive correlation. The publication data can be compared with some other measures, two of which are selected for analysis here. Rank-order correlation is calcu-

ior positions, and tenure and promotion may depend on their publication records. In addition, there have been shifts at some universities to hire individuals who are not on the tenure track. These individuals may be in nonpermanent positions. If there have been such moves in recent years, the remaining faculty may be more productive. This factor may affect per capita publications but may not explain increases in total publications. To reiterate, these are only speculations.

Other analyses of the ARL data are possible. Rank-order correlations can be cal- lated for total publications and volumes held by the ARL institutions' libraries. The resulting coefficient is .70, which suggests that there is some variance in the two ranked lists. The coefficient for per capita publications and volumes in the libraries is .40 , a rather weak correlation. When the ranked list of institutions by total publications is compared with that for numbers of doctorates awarded, the coefficient is .83 . The coefficient for per capita publications compared with doctorates awarded is .45 . Table 3 presents a comparison of the correlation coefficients for the two time periods.

\begin{tabular}{|lcc|}
\hline \multicolumn{3}{|c|}{ TABLE 3 } \\
\multicolumn{3}{|c|}{ Rank-Order Correlations (ARL Institutions): Comparisons over Time } \\
\hline \hline & $1991-1993$ & $1995-1997$ \\
\hline Total Publications by Volumes in Libraries & .69 & .70 \\
Per Capita Publications by Volumes in Libraries & .42 & .40 \\
Total Publications by Doctorates Awarded & .79 & .83 \\
Per Capita Publications by Doctorates Awarded & .48 & .45 \\
\hline
\end{tabular}




\begin{tabular}{|llll|}
\hline \multicolumn{4}{c}{$\begin{array}{c}\text { TABLE 4 } \\
\text { Top Twenty ACRL Institutions Compared: } \\
\text { Total Number of Publications }\end{array}$} \\
\hline \hline & & & \\
& & & $1995-1997$ \\
Tufts & & & \\
Virginia Commonwealth & 2,883 & Tufts & 3,811 \\
Carnegie Mellon & 2,521 & Virginia Commonwealth & 2,816 \\
South Florida & 2,372 & Carnegie Mellon & 2,744 \\
Kansas State & 2,359 & South Florida & 2,678 \\
Vermont & 2,006 & Kansas State & 2,313 \\
Louisville & 1,702 & West Virginia & 1,965 \\
West Virginia & 1,557 & Vermont & 1,851 \\
St. Louis U. & 1,515 & St. Louis U. & 1,846 \\
UC Santa Cruz & 1,485 & UC Santa Cruz & 1,832 \\
Clemson & 1,447 & Louisville & 1,663 \\
Wisconsin-Milwaukee & 1,358 & Clemson & 1,528 \\
Northeastern & 1,296 & Northeastern & 1,528 \\
Rhode Island & 1,259 & Wisconsin-Milwaukee & 1,515 \\
Baylor & 1,255 & Rhode Island & 1,399 \\
Utah State & 1,224 & Utah State & 1,363 \\
Arkansas & 1,147 & Nevada-Reno & 1,347 \\
Nevada-Reno & 1,057 & Arkansas & 1,233 \\
Wyoming & 1,024 & North Texas & 1,148 \\
Akron & 1,017 & Lehigh & 1,139 \\
& 1,014 & New Mexico State & 1,102 \\
\hline
\end{tabular}

In the previous study, it was found that chi-square tests performed on pairs of variables-publications by volumes in the libraries, publications by total library expenditures, per capita publications by volumes, per capita publications by total expenditures, and other library measures-resulted in no statistically significant differences. Because of the earlier findings and the similarities between the trends evident in the two time periods, the chi-square tests are not performed here.

\section{Findings: ACRL Institutions}

ACRL institutions are included in the present study in order to gain insight into whether the trends that are evident among ARL institutions occur in other universities. Because the ACRL institutions are not research universities, it can be expected that the level of publishing productivity is not as high as it is at the ARL universities. This expectation is realized, but there is still an increase in publishing activity from one time period to the other. The mean number of total publications per institution in $1991-1993$ is 874.0 (the range is 149 to 2883 ). The mean for 1995-1997 is 1074.9 (with a range of 165 to 3811 ). The top twenty institutions for each time period are presented in table 4.

An upward trend also is apparent with regard to per capita publications. The mean for the earlier period is 1.59 (the range is .49 to 9.55); the mean for the later time frame is 1.78 (with a range of .42 to 12.33). Top twenty institutions are presented in table 5 .

As is the case with the ARL data, these figures allow for the testing of some hypotheses. The two hypotheses regarding the data from the two time periods (stated as null hypotheses) are similar to those expressed above:

$\mathrm{H}_{1}$ There is no statistically significant difference between the mean number of publications per institution for the two time periods. 


\section{TABLE 5}

Top Twenty ACRL Institutions Compared: Per Capita Publications

\begin{tabular}{lllr}
\hline \hline \multicolumn{1}{c}{ 1991-1993 } & & \multicolumn{2}{c}{$1995-1997$} \\
Tufts & 9.55 & Tufts & 12.33 \\
Carnegie Mellon & 4.30 & Carnegie Mellon & 4.79 \\
Clarkson & 3.83 & UC Santa Cruz & 4.51 \\
UC Santa Cruz & 3.37 & Clarkson & 3.96 \\
Virginia Commonwealth & 3.16 & St. Louis U. & 3.61 \\
Vermont & 2.90 & Alaska-Fairbanks & 3.18 \\
Texas-Dallas & 2.48 & Lehigh & 2.85 \\
Lehigh & 2.32 & Nevada-Reno & 2.72 \\
Kansas State & 2.31 & Vermont & 2.52 \\
Baylor & 2.08 & Drexel & 2.37 \\
Utah State & 2.02 & Rhode Island & 2.22 \\
Nevada-Reno & 2.00 & Montana State & 2.12 \\
Rhode Island & 1.91 & Colorado School of Mines & 2.10 \\
Colorado School of Mines & 1.85 & Northeastern & 2.05 \\
Idaho & 1.83 & Texas-Dallas & 1.95 \\
Drexel & 1.79 & Kansas State & 1.92 \\
Missouri-Rolla & 1.77 & Utah State & 1.90 \\
St. Louis U. & 1.77 & Virginia Commonwealth & 1.88 \\
Wyoming & 1.70 & Wisconsin-Milwaukee & 1.84 \\
Clark & 1.69 & SUNY Binghamton & 1.81 \\
\hline
\end{tabular}

$\mathrm{H}_{2}$ There is no statistically significant difference between the mean per capita number of publications for the two time periods.

The type I error level (the probability of rejecting a true null hypothesis) again is set at 0.05 .

Once again, a paired t-test is used to determine statistical significance. In the first case, the mean number of publications per institution, the calculated probability is less than 0.006 . In the second case, the mean per capita number of publications, the calculated probability is less than 0.01 . The results are in keeping with those for the ARL data. Both of the null hypotheses are rejected; there are statistically significant differences between the two time periods. The speculations offered above with regard to publishing by faculty at the ARL institutions also may hold with this population. There also may be increasing pressure to publish at universities that do not have a historically strong research emphasis.
Rank-order correlations also can indicate some relationships within the publication data and between those data and other measures. When the two time peri-

\section{Faculty constitute a large and politically influential segment of the campus community.}

ods are compared, there tends to be a fairly strong positive correlation. The coefficient for total publications is .88; the coefficient for per capita publications is .72. The indications of these tests are that the patterns exhibited by the ARL institutions also are present with the ACRL institutions, although the ACRL correlations are a bit less strong. Further comparisons can be made between the publishing data and the numbers of volumes in the libraries and numbers of doctorates awarded. These comparisons are presented in table 6 .

As is apparent from the table, the correlations are not strong, suggesting that 


\begin{tabular}{|c|c|c|}
\hline \multicolumn{3}{|c|}{$\begin{array}{c}\text { TABLE } 6 \\
\text { Rank-Order Correlations (ACRL Institutions): Comparisons over Time } \\
\end{array}$} \\
\hline & $1991-1993$ & 1995-1997 \\
\hline Total Publications by Volumes in Libraries & .28 & .36 \\
\hline Per Capita Publications by Volumes in Libraries & .05 & .00 \\
\hline Total Publications by Doctorates Awarded & .42 & .44 \\
\hline Per Capita Publications by Doctorates Awarded & .11 & .12 \\
\hline
\end{tabular}

there is little connection between the measures of library holdings and doctorates awarded and those of publishing productivity.

\section{Discussion}

It is evident from the results presented here that faculty members at research universities and at universities without a traditional research emphasis are publishing greater numbers of items. The reasons for the increases, as stated above, are matters for speculation. However, the increases are of interest to academic librarians. Faculty constitute a large and politically influential segment of the campus community. Their behavior patterns almost inevitably have an impact on the focus of the library. If those behavior patterns are changing, it behooves academic librarians to consider the nature of those changes and their possible effects on services, collections, and access mechanisms. Even a change in magnitude, such as the one suggested in this paper, may be important to the libraries on these campuses.

However, there are other, more complex, potential implications of these findings. At the present time, everyone engaged in research and scholarship-and the communication of the fruits of that research and scholarship-is concerned about the means of communication. Publication in print has some inherent limitations, as well as some definite costs. On the other hand, faculty are publishing in print in increasing numbers. Everyone involved in the scholarly communication system needs to investigate whether the increase signals an affinity for the traditional means of communicating or whether it signals a set of behaviors that are constrained by the avenues of communication which are currently open and by the rewards structures of individual campuses. There is no doubt that existing and emerging technologies can offer potential outlets for formal communication of research and scholarship. However, some essential points still need to be resolved, including:

- Can the technology provide sufficient access to the products of scholarly work?

- Is the technological solution more economical than print?

- Is the technological solution more effective than print for all academic disciplines?

- Can the institutions transform their rewards structures to accommodate a variety of publication media?

These are not the only questions that need to be addressed, but they provide a starting place. As deliberations and conversations progress, these questions should be addressed within the context of increasing publishing productivity by faculty. As principals involved in the production of publications, the faculty should be involved in the decision-making processes that will shape scholarly communication. The data and findings presented here can provide something of a context in which the discussion can continue.

\section{Notes}

1. Stephen J. Bensman and Stanley Wilder, "Scientific and Technical Serials Holdings Optimization: 
A LSU Serials Redesign Project Exercise," Library Resources \& Technical Services 42 (July 1998): 147-242. 2. See the SPARC Web site at: http://arl.cni.org/sparc/.

3. Stephen D. Gruning, "Research, Reputation, and Resources: The Effect of Research Activity on Perceptions of Undergraduate Education and Institutional Resource Acquisition," Journal of Higher Education 68 (Jan.-Feb. 1997): 17-52.

4. Meredith Jane Ludwig, "Framing the Public Policy Debate on Faculty: What Is the Role of Research?" New Directions for Institutional Research, no. 90 (summer 1996): 67-77.

5. John M. Braxton and Joseph B. Berger, "Public Trust, Research Activity, and the Ideal of Service to Students As Clients of Teaching," New Directions for Institutional Research, no. 90 (summer 1996): 79-91.

6. Ernest L. Boyer, Scholarship Reconsidered: Priorities of the Professoriate (Princeton, N.J.: Carnegie Foundation for the Advancement of Teaching, 1990).

7. Charles E. Glassick, Mary Taylor Huber, and Gene I. Macroff, Scholarship Assessed: Education of the Professoriate (San Francisco: Jossey-Bass, 1997).

8. John M. Budd, "Faculty Publishing Productivity: An Institutional Analysis and Comparison with Library and Other Measures," College E Research Libraries 56 (Nov. 1995): 547-54. Data and findings related to ARL institutions for the 1991-1993 time period are taken from this source. 